\title{
Cost of Paediatric Diabetes Mellitus Treatment on Carers of Diabetic Children Attending Three Hospital Out-Patient Clinics in Zimbabwe
}

\author{
Article by Pasipanodya Ian Machingura ${ }^{1}$, Ismail Ticklay ${ }^{2}$, Robson Dembah ${ }^{3}$, Fredrick Richard \\ Heller $^{4}$ \\ ${ }^{1,3}$ Department of Medical Laboratory Sciences, University of Zimbabwe College of Health \\ Sciences \\ ${ }^{2}$ Department of Paediatrics, University of Zimbabwe College of Health Sciences \\ ${ }^{4}$ People's Open Access Education Initiative \\ E-mail:imachingura@yahoo.co.uk
}

\begin{abstract}
There is paucity of information on the economic impact of diabetes mellitus in low and middle income countries, including Zimbabwe. The study sought to determine the patient treatment cost of paediatric diabetes mellitus on families of diabetic children attending Parirenyatwa, Harare and Chitungwiza hospital out-patient clinics in Zimbabwe.

A cross sectional study was conducted at Parirenyatwa, Harare and Chitungwiza hospitals between 10 May 2017 and 27 September 2017 in which all paediatric diabetic patients and carers were given the information on the study. A questionnaire was administered on all carers of paediatric diabetic patients' who consented to participate in the study.

Only (36/85) 42\% of the carers of paediatric diabetes mellitus children, who had attended the outpatient clinic in the year preceding the study at least once at Parirenyatwa, Harare and Chitungwiza hospital were accessed. Only $53 \%$ of the 36 children had a measure of glycaemic control, of whom 74\% had HbAlc $\geq 7.5 \%$ indicating poor glycaemic control. Cash was the mode of payment used by the majority of the carers for child treatment, and the monthly expenditure was almost half of the family total income.

This study indicates a considerable portion of the family income is spent in child care of diabetic children and loss of productive time due to child care. Only a small proportion of the children was accessed during the study population which can be attributed to financial problems limiting clinic attendance. There was poor diabetic control amongst the paediatric diabetic patients who had HbAlc results.
\end{abstract}

Keywords: diabetes mellitus, diabetes mellitus cost, paediatric diabetes mellitus.

\section{Introduction}

Worldwide diabetes mellitus prevalence is on the rise and Sub Saharan Africa is considered an emerging hotspot (1). Type 1 diabetes mellitus is estimated to develop in 86000 children under 15 years annually in the whole world. There are sparse reliable data on type 2 diabetes mellitus in children and adolescents. However with increasing levels of obesity and physical inactivity amongst children in many countries type 2 diabetes mellitus in childhood has potential of becoming a global public health issue leading to serious health outcomes (2).

Diabetes mellitus does exert a heavy economic burden. The burden is related to health systems costs which are incurred by the society in the management of the disease, indirect costs due to productivity losses caused by patient disability and premature mortality, time spent by family members accompanying the patients when they are seeking medical care and intangible costs (3). Part of the family budget is used to treat diabetes mellitus every month (4). Poverty on a personal scale limits family affordability of insulin, glucose monitoring strips and other equipment. In situations where they are no available state funding for healthcare families have to pay for these supplies which may result in need for a harsh choice between medicines and food (5).

In Mali it was reported that the total medical cost of diabetic patients were almost 4 times higher than the total costs in those without diabetes mellitus which is higher than that found in developed countries 
where a ratio reported are between 2.0 and 2.4 (6). In Africa the testing for diabetes mellitus is usually conducted after patients present with complications known to arise from diabetes mellitus. Thus patients recognised as diabetic in Africa are much sicker and need more services and medication as compared to their counterparts in other parts of the world (6).

Africa is faced with poverty and mostly out of pocket payment is the mode of payment which is used to pay for the hospital expenses by the majority of the people. In 2010 Idemyor highlighted the limitation of studies on economics of diabetes mellitus care in Sub Saharan Africa (Idemyor, 2010): surprisingly, seven years later, the situation is still the same. There is paucity of data on the cost of treatment of paediatric diabetes mellitus in Africa, hence the need to estimate the cost of diabetes mellitus in children to aid in prioritising interventions carried out with limited available resources (Bermudez-Tamayo et al., 2017). In Zimbabwe the cost of managing diabetes mellitus is reported to be escalating (7). Thus the study sought to determine the patient treatment cost of paediatric diabetes mellitus on families of diabetic children attending Parirenyatwa, Harare and Chitungwiza hospital outpatient clinic Zimbabwe.

\section{Materials and methods}

\section{Study design}

A cross sectional study was conducted at Parirenyatwa, Harare and Chitungwiza hospitals between 10 May 2017 and 27 September 2017 in which questionnaires were administered to carers of paediatric diabetes mellitus children attending the out-patient clinic. The carers of the paediatric diabetes mellitus patients were recruited for a once off questionnaire administration in the out-patient clinic. HbA1c measured within the last six months was recorded on the questionnaire.

\section{Study population}

The three hospitals have on the out-patient clinic registers 85 paediatric diabetes mellitus patients who have at least attended the out-patient clinic once in the year preceding the study and had been documented in the registers. The 85 paediatric diabetes mellitus patients were expected to attend the hospital out-patient clinic at least once in three months for the routine diabetes mellitus monitoring visit and to restock their diabetic medication.

\section{Study setting}

Parirenyatwa, Harare and Chitungwiza hospitals are tertiary health care centres which have an outpatient department in which paediatric diabetic patients attend for treatment. These three hospital are also public hospitals and have specialists managing the paediatric diabetes mellitus patients. Parirenyatwa and Harare hospital are in Harare whilst Chitungwiza hospital is located 30km South east of Harare. Harare is the capital city of Zimbabwe.

\section{Study procedures}

All paediatric patients who have been diagnosed with diabetes mellitus and are on regular follow up at Parirenyatwa, Harare and Chitungwiza hospitals out-patients clinic and the children were identified, through a systematic search of hospital records of out-patients clinic attendance register. The clinic nurses and doctors assisted to identify and not miss any paediatric diabetes mellitus patients attending the out-patients clinic, they would notify when a patient comes in outside the regular scheduled clinic time for the out-patient clinic which is Monday, Wednesday and Friday for Parirenyatwa hospital, Wednesday for Chitungwiza hospital and Friday for Harare Hospital. The out-patient clinics do not have a log of the children expected on a particular visit thus the author would not know children who missed a visit per particular session during the study period of 10 May 2017 to 27 September 2017.

\section{Inclusion criteria}

- All diabetes mellitus patient minimum age 18 months and less than 18 years who were on treatment for diabetes mellitus in the out-patient clinic at Parirenyatwa, Harare and Chitungwiza hospital during the study period. 
- Child with diabetes mellitus accompanied by carer who was willing to participate in the study and to give a written informed consent

- Child willing to assent

\section{Exclusion criteria}

- Diabetes mellitus patients more than 18 years old and below 18 months

- Child with diabetes mellitus unaccompanied by a carer

- Carer not consenting to participating in the study

- Child not assenting

- Non diabetic children

\section{Sample size calculation}

The sample size was determined by the number of paediatric diabetes mellitus patients' available attending the out-patient clinic at Parirenyatwa, Harare and Chitungwiza hospital.

\section{Data analysis}

The data were captured on an excel spread sheet and analysed using SPSS version 16. Descriptive statistics was used to summarize demographic characteristics, patients' clinical characteristics and financial costs. The mean and standard deviation was used to summarise data which were normally distributed. Median and interquartile range was used to summarise non-normally distributed data. The student's $t$ test was used to compare continuous variables whereas chi squared test was used for categorical data. A p value of less than 0.05 was considered statistically significant.

\section{Definitions}

The target for HbA1c of less than 7.5\% for all age groups (International Diabetes Federation, 2011), thus poor control, was defined as HbA1c $\geq 7.5 \%$ (López-Bastida et al., 2017). Diabetes mellitus complication in the past six months was based on response to a question on the presence of diabetes mellitus complications in the past six months, confirmed by the children treatment records. One United States of America dollar was equivalent to one Zimbabwe dollar during the study period.

\section{Ethical consideration}

The study was approved by both the Joint Parirenyatwa hospital and University of Zimbabwe Joint Ethics committee, Harare hospital, Chitungwiza hospital and the Medical Research Council of Zimbabwe. The paediatric patients and carers had the study procedures explained to them. Carers of paediatric diabetes mellitus patients as legal representatives of the patients were asked to give consent. All the carers of paediatric diabetes mellitus patients who consented to participate in the study were asked to sign a consent form whilst children who aged 7 years and above were asked to give assent.

\section{Results}

A total of thirty six children were recruited during the study period of 10 May 2017 to 27 September 2017 from Parirenyatwa, Harare and Chitungwiza hospitals, despite efforts to track the children at all the three hospitals during the course of the study. Of these 36 children $89 \%$ (32/36) were from Parirenyatwa hospital, 8\% (3/36) from Harare hospital and 3\% (1/36) from Chitungwiza hospital. Using the clinic registers of the out-patient clinics indicating children with diabetes mellitus who had been to the out-patient clinic at least once in the year preceding the study at Parirenyatwa hospital only $76 \%$ (32/42), Harare hospital 8\% (3/38) and Chitungwiza hospital 25\% (1/5) of the children were accessed during the course of this study. There were 3 carers ( 1 was from Parirenyatwa hospital and 2 were from Chitungwiza hospital) who did not consent to participate in the study and 2 children (Both from Parirenyatwa hospital) who did not come with a carer during the clinic visits and could not be enrolled into the study. The other children who could not be seen and tracked in the out-patient clinic during the course of the study records are not available since paper based records which the patient caries are used at all the three hospitals.

The Clinical and demographic characteristics of the children enrolled into the study are shown in table 1 . The mean age of children was 11.8 years and the mean age at diagnosis is 9.5 years. There were 
DOI: 10.21522/TIJPH.2013.05.04.Art064

ISSN: $2520-3134$

more female $56 \%$ (20/36) than male children. The median duration of diabetes mellitus was 1.08 years. The majority of the children were on actraphane $81 \%(29 / 36)$ and $22 \%(8 / 36)$ of the children had had their medication changed to the current medication they were taking.

Only 53\% (19/36) of the children had results for HbA1c, whose mean HbA1c was $9.6 \%$ and the majority of the children $74 \%$ (14/19) had HbA1c $\geq 7.5 \%$. During the clinic visit 97\% (35/36) had a glucose measurement using a glucometer whose mean was $9.37 \mathrm{mmol} / \mathrm{L}$. Development of a diabetes mellitus complication in the past six months was reported by $69 \%(25 / 36)$ of the children. The majority of the children $67 \%$ (24/36) were brought to the clinic by their mother, whilst $25 \%(9 / 36)$ were brought by the father, $3 \%(1 / 36)$ by maternal grandmother, $3 \%(1 / 36)$ by sister and $3 \%(1 / 36)$ by brother who indicated they were carers of the children responsible for most of the day to day care of the children.

Table 1. Clinical and demographic characteristics of the children enrolled into the study, measures made at the enrolment visit $(\mathrm{N}=36)$

\begin{tabular}{|c|c|}
\hline Age, years mean, standard deviation & $11.81 \pm 3.88$ \\
\hline $\begin{array}{l}\text { Age at diagnosis, years mean, standard } \\
\text { deviation }\end{array}$ & $9.51 \pm 4.00$ \\
\hline Sex Female n $(\%) /$ Male n $(\%)$ & $20(56 \%), 16(44 \%)$ \\
\hline $\begin{array}{l}\text { Duration of disease, years median, } \\
\text { interquartile range }\end{array}$ & $1.08,0.42-2.77$ \\
\hline $\begin{array}{l}\text { Medication } \\
\text { Actraphane, n (\%) } \\
\text { Protaphane and actrapid, n (\%) } \\
\text { Actraphane and actrapid, n (\%) } \\
\text { Novorapid and levimir, n (\%) } \\
\text { Levimir, n (\%) } \\
\text { Diet, n (\%) }\end{array}$ & $\begin{array}{l}29(81 \%) \\
3(8 \%) \\
1(3 \%) \\
1(3 \%) \\
1(3 \%) \\
1(3 \%)\end{array}$ \\
\hline $\begin{array}{l}\text { Ever changed diabetes medication, } \mathrm{n}(\%) \\
\text { Yes } \\
\text { No }\end{array}$ & $\begin{array}{l}8(22 \%) \\
28(78 \%)\end{array}$ \\
\hline HbA1c, \% mean, standard deviation & $9.6(3.3)$ \\
\hline $\mathrm{HbA} 1 \mathrm{c}<7.5 \%, \mathrm{n}(\%)$ & $5(26 \%)$ \\
\hline $\mathrm{HbA} 1 \mathrm{c} \geq 7.5 \%, \mathrm{n}(\%)$ & $14(74 \%)$ \\
\hline Glucose, mmol/L mean, standard deviation & $9.37 \pm 7.49$ \\
\hline $\begin{array}{l}\text { Diabetes complication, } \mathrm{n}(\%) \\
\text { Yes } \\
\text { No }\end{array}$ & $\begin{array}{l}25(69 \%) \\
11(31 \%)\end{array}$ \\
\hline
\end{tabular}

A majority of the children 67\% (24/36) had their payment for health care by cash. The mean payment made for hospital consultation for those who paid cash for the past six months was $\$ 22.58$ and the child medication cost for the past six months was $\$ 84.00$. The median monthly out of pocket expenditure for the children was $\$ 63.50$. Three quarters $(27 / 36)$ of the carers indicated that they buy special food for the children. The mean cost of the money spent on special food in the past six months by 27 carers who buy special food for was $\$ 179.15$. In the past six months $44 \%$ (16/36) of the children were hospitalised for a median days 14 and 63\% (10/16) of them paid cash whose mean was $\$ 744.30$. The median cost for those who paid for laboratory investigation by cash was $\$ 27.00$. Of all the children four $(11 \%)$ had other health procedure conducted in the past six months of which three it was eye examination and one it was an $\mathrm{x}$ ray scan. Twelve children $(33 \%)$ had a requested medical procedure not done in the past six months due to unavailability of money, majority $58 \%$ (7/12) of the procedure not done was HbA1c (Table 2).

The median transport cost for review for the past six months was $\$ 11.00$ whilst the median transport cost to buy medication for the past six months was $\$ 4.5$. The median school days missed by the children was 6.0 days. The median time spent by carer attending to the child was 1.00 hour per day. The median carer monthly income was $\$ 135$ whilst that the median total family income was $\$ 150$ (Table 2). 
Table 2. Cost evaluation

\begin{tabular}{|c|c|}
\hline $\begin{array}{l}\text { Mode of payment for health care costs } \\
\text { Cash, } \mathrm{n}(\%) \\
\text { Medical aid, } \mathrm{n}(\%) \\
\text { Social welfare, } \mathrm{n}(\%) \\
\text { Exempt }\end{array}$ & $\begin{array}{l}24(67 \%) \\
9(25 \%) \\
2(6 \%) \\
1(3 \%)\end{array}$ \\
\hline $\begin{array}{l}\text { Hospital consultation cost for the past six } \\
\text { months, \$ mean, standard deviation }\end{array}$ & $22.58 \pm 11.43$ \\
\hline $\begin{array}{l}\text { Child medication cost for the past six months, } \\
\$ \text { median, interquartile range }\end{array}$ & $84.00(47.25-124.5)$ \\
\hline $\begin{array}{l}\text { Monthly out of pocket expenditure per month, } \\
\$ \text { median, interquartile range }\end{array}$ & $63.50(50.00-115.25)$ \\
\hline $\begin{array}{l}\text { Buy special food for the past six months, } \mathrm{n} \\
(\%) \\
\text { Amount spent on special food, } \$ \text { mean, } \\
\text { standard deviation }\end{array}$ & $\begin{array}{l}27(75 \%) \\
179.15 \pm 135.73\end{array}$ \\
\hline $\begin{array}{l}\text { Children hospitalised in past six months, } \mathrm{n} \\
(\%) \\
\text { Days children were hospitalised, days median, } \\
\text { interquartile range } \\
\text { Paid cash for hospital fee, } \mathrm{n}(\%) \\
\text { Hospital cost, } \$ \text { mean }\end{array}$ & $\begin{array}{l}16(44 \%) \\
14(9.25-19.0) \\
10(63 \%) \\
744.30 \pm 594.52\end{array}$ \\
\hline $\begin{array}{l}\text { Laboratory investigations in the past six } \\
\text { months cost } \\
\text { Median for those who paid cash } \$ \text {, } \\
\text { interquartile range }\end{array}$ & $27.00(16.00-63.50)$ \\
\hline $\begin{array}{l}\text { Other health care cost in the past six months } \\
\text { Yes } n(\%) \\
\text { Eye examination } \\
\text { X ray scan } \\
\text { Median cost } \$ \text { of other procedure, } \\
\text { interquartile range }\end{array}$ & $\begin{array}{l}4(11 \%) \\
3(8 \%) \\
1(3 \%) \\
11.50(10.00-44.50)\end{array}$ \\
\hline $\begin{array}{l}\text { Health care procedure not done due to } \\
\text { unavailability of money } \\
\text { Yes, } \mathrm{n}(\%) \\
\text { Eye examination } \\
\text { Spectacles } \\
\text { HbA1c } \\
\text { Missed review }\end{array}$ & $\begin{array}{l}12(33 \%) \\
2(6 \%) \\
1(3 \%) \\
7(19 \%) \\
2(6 \%)\end{array}$ \\
\hline $\begin{array}{l}\text { Transport cost for the past six months } \\
\text { For review, \$ median, interquartile range } \\
\text { To buy medication, \$ median, interquartile } \\
\text { range }\end{array}$ & $\begin{array}{l}11.00(4.00-27.50) \\
4.50(0.00-12.00)\end{array}$ \\
\hline $\begin{array}{l}\text { Days carer missed work in past six months, } \\
\text { days median, interquartile range }\end{array}$ & $4.5(0.00-10.75)$ \\
\hline $\begin{array}{l}\text { Days child missed school in past six months, } \\
\text { days median, interquartile range }\end{array}$ & $6.0(0.00-30.00)$ \\
\hline $\begin{array}{l}\text { Time spent by carer attending to child per } \\
\text { day, hours median, interquartile range }\end{array}$ & $1.00(0.44-3.00)$ \\
\hline Income & $135.00(50.00-387.00)$ \\
\hline
\end{tabular}


DOI: $10.21522 /$ TIJPH.2013.05.04.Art064

ISSN: $2520-3134$

\begin{tabular}{|l|l|}
\hline $\begin{array}{l}\text { Carer per month, \$ median, interquartile } \\
\text { range } \\
\text { Total family income per month, \$ median, } \\
\text { interquartile range }\end{array}$ & $150.00(100.00-524.50)$ \\
\hline
\end{tabular}

\section{Discussion}

In this cross sectional study at Parirenyatwa, Harare and Chitungwiza hospitals, carers of paediatric diabetes mellitus patients attending the out-patient clinic during the study period of 10 May 2017 to 27 September 2017 were interviewed. According to the registers of the out-patient clinics, fewer than half of the children with diabetes mellitus who had been to the out-patient clinic at least once in the year preceding the study were seen in this study. This is despite efforts to track the children at all the three hospitals by the author during the course of the study. The records of other children who could not be seen and tracked in the out-patient clinic during the course of the study are not available since paper based records which the patient caries are used at all the three hospitals. However in order to explore the experience of the population of children with diabetes mellitus and the associated cost availability of records is crucial to enable the information to feed into health policy. Despite this limitation this study is an important exploratory study on the cost of care of paediatric diabetes mellitus in three tertiary hospitals in Zimbabwe.

A majority of the children (81\%) were on actraphane. $74 \%$ of the children who had HbAlc results had poor glycaemic control. $69 \%$ of the children reported a diabetic complication. Poor glycaemic control may cause episodes of hypoglycaemia which can affect developing nervous system and children with diabetes mellitus who are aged less than 7 years are at risk of cognitive dysfunction (10). In this study $74 \%$ of the children who had HbAlc had a result $\geq 7.5 \%$ indicating poor metabolic control which is contrary to a study in Spain where $60 \%$ of the children had a HbAlc $<7.5 \%$ (López-Bastida et al., 2017). In western countries better metabolic control is achieved due to better access to medication and testing as evidenced by higher number of children with better metabolic control in a study in Spain when compared to a study in Nairobi Kenya. In a study in Nairobi Kenya similar to this study $28 \%$ of the children and adolescents achieved a reasonable glycaemic control, even though they used a cut off for poor control of HbA1c higher than 8\% (12). Similarly in a study in Khartoum Sudan glycaemic control was poor in $86 \%$ of the children (Elrayah et al., 2005). In this present study a majority (Table $2,7 / 12$ children) (58\%) who had a requested procedure not done in the past six months indicated they failed to have an $\mathrm{HbAlc}$ done due to unavailability of money.

A majority of the children, $67 \%$, were brought by their mother, similar to a study in Nairobi Kenya where a majority of the children had a parent as primary care giver. Parents are more committed to their children with chronic illness and ensure better compliance with medication (Ngwiri et al., 2015). The children with parental care might enjoy stable family structure which is more supportive (Ngwiri et al., 2015).

The major acute complication in children with diabetes mellitus is reported to be diabetes ketoacidosis. In the presence of poor glycaemic control, diabetic ketoacidosis episodes can be frequent leading to emergency department visits and admission to intensive care units. Diabetes ketoacidosis and other diabetes mellitus complications such as hypoglycaemia, can be reduced by comprehensive, multidisciplinary approach in disease management (Ilkowitz et al., 2016). In this study (Table 2) 44\% of the children were admitted into the hospital in the past six months for median days 14 and the 10 patients who paid cash paid a mean cost toward admission of $\$ 744.30$.

In this current study (Table 2) the median monthly expenditure for child treatment was reported to be $\$ 63.50$ against a total family median monthly income of $\$ 150.00$. Thus there is very high healthcare expenditure in relation to income beyond which the families begin to make sacrifice items of basic consumption. Financial catastrophe is predicted due to health care cost paid out of pocket, inability to pay and absence of prepayment mechanisms to enable the pooling of financial risks (Bermudez-Tamayo et al., 2017). The diabetes mellitus care cost can be devastating for the families. The poorer families cost of diabetes mellitus consumables for minimum care take all family income leaving no money for food, shelter and clothing. Hence some families have to sell assets or borrow, however in this study we did not ask questions on asset disposal or borrowing of money to manage diabetes mellitus. Many carers 
have to make chilling choices under principle of opportunity cost such as would they cover cost of diabetic care of affected child or provide education for their other children. It reported that in some settings to offset the high cost and increase time until more insulin is purchased, insulin doses are often missed or reduced (Ogle et al., 2016).

Of the paediatric patients with diabetes mellitus who had attended the out-patient clinic in the year preceding the study at least once at Parirenyatwa, Harare and Chitungwiza hospitals, in this study we accessed only (36/85) $42 \%$. The inability to get the other children in the hospitals in this study could also be attributed to financial challenge hence the children do not come for their regular follow up visit. It is a cause of concern whether they are able to adhere to the treatment regimens. The International Society for Paediatric and Adolescent Diabetes recommends HbA1c monitoring four to six times a year for younger children and three to four times a year in older children. The target for HbAlc of less than $7.5 \%$ for all age groups (International Diabetes Federation, 2011), only 53\% of the children had an HbA1c measurement, of whom only $26 \%$ were less than $7.5 \%$. The barriers to care for diabetic children include psychosocial instability which encompass broken homes, detrimental health beliefs, poor adjustment to diabetes mellitus diagnosis, financial, limitation or the inconstancy in the access to insulin, food, supplies and care (Pihoker et al., 2014). Thus some diabetic children may not be coming to their routine monitoring visits due to cost and those who attended the clinic had poor glucose control.

In the current study in a majority (67\%) of the children payment for hospital care was by cash with medical aid being used by few children (25\%). In a study at University of Benin Teaching Hospital in Nigeria (2011), it was reported that only $10 \%$ of parents with children with diabetes mellitus indicated that they could cope with health care payments. The families consumption and investment needs are sacrificed because health care needs cannot be ignored hence the need to protect poorer users against the excessive health care expenditures (Onyiriuka, Ezomo, \& Onyiriuka, 2013). On the contrary governments in high income countries usually do provide diabetes mellitus supplies free or at an affordable price which is subsidized as opposed to low income countries with under resourced medical system (Ogle et al., 2016).

Medical aid facility is a way to pool resources and cushion oneself from health care cost. The medical aid in Zimbabwe works on the basis of employer and employee monthly contributions. The delivery platform of the medical aid is segmented based on net worth or contribution, there are executive, private and general statuses varying in reimbursement value and health services access. Only $10 \%$ of Zimbabwean population have medical aid whilst the urban and rural poor cannot access specialist health care unless they pay using out of pocket payment (Mugwagwa, 2017).

Government support to families who are unable to cope is available in the form of social welfare. Only $6 \%$ of the children were using social welfare to cover their hospital expense and $3 \%$ were exempt from paying hospital fees. This is a cause of concern considering that the median total family income was $\$ 150$, which has to cover living expenses for the families and the child treatment.

Child median medication cost for the past six months (Table 2) was $\$ 84$ against a six months median salary of carer of $\$ 810(\$ 135 \times 6)$ and total family income for six months $\$ 900$ ( $\$ 150 \times 6)$ which is $10 \%$ (84/810) of the carer income and 9\% (84/900) of total family income. This is lower than $43.7 \%$ which was reported from University of Benin Teaching hospital in 2011 (Onyiriuka, Ezomo, \& Onyiriuka, 2013).

The median days of child missing school in the past six months (Table 2) was six days, which is which is higher than the reported days which children with type 1 diabetes mellitus miss school which is 3.7 days yearly (López-Bastida et al., 2017). A systematic review of the evidence on which type 1 diabetes mellitus affect education, employment and income later in life demonstrated that children who have diabetes mellitus miss more school compared to other children. The absence from school is common when diabetes mellitus is first diagnosed as children may be admitted to hospital for treatment and education on blood glucose control. School attendance is affected by stress, poor metabolic control and diabetic complications. The absence from school could have deleterious effects on academic performance, peer relationships, social performance, intelligence quotient and self-esteem. The effect on academic achievement could affect subsequent success in the labour market, as school leavers who have few or no qualifications are at greater risk of unemployment in adulthood. The adverse socioeconomic outcomes might in turn be hazardous to health causing further damage to health in a 
DOI: $10.21522 /$ TIJPH.2013.05.04.Art064

ISSN: $2520-3134$

downwards spiral. If any of the adverse social consequences were more severe for the children who were already disadvantaged this could exacerbate the existing social inequalities amongst adults (Milton, Holland, \& Whitehead, 2006).

The carers were unable to work 4.5 days in six months due to the child illness and also use 1.00 hours a day to attend to the child (Tabl2 2). Management of diabetes mellitus places substantial demands on the families and providers of care. Contemporary management of diabetes requires both close collaboration with families who perform day to day management tasks and coordination of the care between specialists, primary care providers, schools and day care. Given demands of management of diabetes mellitus families might experience impacts in areas of work, finances, time and school attendance (Katz et al., 2012). The time which is dedicated to childcare because of diabetes mellitus may be considerable. In these cases burden of care and opportunity cost of time spent on the informal care can be highly relevant costs from the perspective of society (López-Bastida et al., 2017). Diabetes mellitus does impact negatively on working productivity (Bermudez-Tamayo et al., 2017).

The major limitation of the study is the sample size. There were never going to be enough children to provide a confident estimate of costs, due to the small number of children with diabetes mellitus being managed at these health care facilities and only a small proportion of the children were accessed during the study period. The information from carers was also not validated by other sources. Thus the results of this study should be considered as exploratory. However the findings suggest a serious problem of the control of diabetes in these children, very likely associated with the high costs of care relative to family income. The findings should be adequate to feed into local health policy making as well as to serve as a basis for further research.

\section{Conclusion}

This study is an exploratory analysis on the cost of diabetes mellitus in children in Zimbabwe. The study demonstrates that the cost of diabetes mellitus constitutes a huge burden on the families. In situations where there is no publicly funded healthcare system for diabetes mellitus treatment, health care costs are borne almost entirely by families. The monthly amount spent on health care of children with diabetes mellitus is a considerable portion of the total family income - hence the provision of government funded or subsidised treatment could cushion the families from the economic impact of diabetes mellitus. There was poor clinic attendance amongst the paediatric diabetic children which could be due to financial challenge. There was also poor glycaemic control amongst the paediatric diabetes mellitus patients studied.

\section{References}

[1]. Bermudez-Tamayo C, Besançon S, Johri M, Assa S, Brown JB, Ramaiya K. Direct and indirect costs of diabetes mellitus in Mali: A case-control study. Bouchama A, editor. PLOS ONE. 2017 May 18; 12(5):e0176128.

[2]. Castro A del RV, Grossi SAA. Cost of diabetes mellitus type 1 treatment: difficulties of the families. Acta Paul Enferm. 2008; 21(4):624-8.

[3]. Diabetes Leadership Forum, Africa. Diabetes: the hidden pandemic and its impact on sub-saharan africa. 2010.

[4]. International Diabetes Federation. International Diabetes Federation Atlas (Sixth edition). 2013.

[5]. International Diabetes Federation. International Diabetes Federation Seventh Edition [Internet]. 2015 [cited $2016 \mathrm{Jul}$ 20]. Available from: www.diabetesatlas.org.

[6]. Ilkowitz JT, Choi S, Rinke ML, Vandervoot K, Heptulla RA. Pediatric Type 1 Diabetes: Reducing Admission Rates for Diabetes Ketoacidosis. Qual Manag Health Care. 2016; 25(4):231-7.

[7]. International Diabetes Federation. Global IDF/ISPAD guideline for diabetes in childhood and adolescence. [Internet]. 2011 [cited 2016 Jul 20]. Available from: https://www.idf.org/sites/default/files/Diabetes-inChildhood-and-Adolescence- Guidelines.pdf

[8]. Katz ML, Laffel LM, Perrin JM, Kuhlthau K. Impact of Type 1 Diabetes Mellitus on the Family is Reduced with the Medical Home, Care Coordination, and Family-Centered Care. J Pediatr. 2012 May; 160 (5):861-7.

[9]. Kirigia JM, Sambo HB, Sambo LG, Barry SP. Economic burden of diabetes mellitus in the WHO African region. BMC Int Health Hum Rights [Internet]. 2009 Dec [cited 2017 Nov 16]; 9(1). Available from: http://bmcinthealthhumrights.biomedcentral.com/articles/10.1186/1472-698X-9-6 
[10]. López-Bastida J, López-Siguero JP, Oliva-Moreno J, Perez-Nieves M, Villoro R, Dilla T, et al. Social economic costs of type 1 diabetes mellitus in pediatric patients in Spain: CHRYSTAL observational study. Diabetes Res Clin Pract. 2017 May; 127:59-69.

[11]. López-Bastida J, López-Siguero JP, Oliva-Moreno J, Perez-Nieves M, Villoro R, Dilla T, et al. Social economic costs of type 1 diabetes mellitus in pediatric patients in Spain: CHRYSTAL observational study. Diabetes Res Clin Pract. 2017 May; 127:59-69.

[12]. Milton B, Holland P, Whitehead M. The social and economic consequences of childhood-onset Type 1 diabetes mellitus across the lifecourse: a systematic review. Diabet Med. 2006 Aug; 23(8):821-9.

[13]. Mugwagwa JT. Private Sector Participation in Health Care in Zimbabwe: What's the Value-Added? J Healthc Commun [Internet]. 2017 [cited 2017 Oct 16]; 02(02). Available from: http://healthcarecommunications.imedpub.com/private-sector-participation-in-health-carein-zimbabwe-whats-the-

valueadded.php?aid $=18546$

[14]. Ngwiri T, Were F, Predieri B, Ngugi P, Iughetti L. Glycemic Control in Kenyan Children and Adolescents with Type 1 Diabetes Mellitus. Int J Endocrinol. 2015; 2015: 1-7.

[15]. Ogle GD, Kim H, Middlehurst AC, Silink M, Jenkins AJ. Financial costs for families of children with Type 1 diabetes in lower-income countries. Diabet Med. 2016 Jun; 33(6):820-6.

[16]. Onyiriuka N, Ezomo OO, Onyiriuka RC. Cost of treating Insulin-requiring diabetes in children and adolescents. J Inst Med. 2013; 34 (1):2-8.

[17]. Pihoker C, Forsander G, Fantahun B, Virmani A, Luo X, Hallman M, et al. The delivery of ambulatory diabetes care to children and adolescents with diabetes: Ambulatory care. Pediatr Diabetes. 2014 Sep; 15(S20):86101.

[18].Zimbabwe Diabetic Association. Zimbabwe Diabetic Association seeking free access to medications. Afr J Diabetes Med. 2016; 24 (1):4. 